\title{
Using Telehealth to Reduce All-Cause 30-Day Hospital Readmissions among Heart Failure Patients Receiv- ing Skilled Home Health Services
}

Melissa O'Connor ${ }^{1,2}$; Usavadee Asdornwised ${ }^{3}$; Mary Louise Dempsey4; Ann Huffenberger ${ }^{4}$; Sandra Jost ${ }^{1}$; Danielle Flynn¹; Anne Norris $^{5}$

${ }^{1}$ Penn Care at Home, University of Pennsylvania Health System;

${ }^{2}$ Villanova University, College of Nursing;

${ }^{3}$ Mahidol University, Bangkok, Thailand;

${ }^{4}$ PENN E-LERT ${ }^{\circledR}$ Telemedicine Program, University of Pennsylvania Health System;

${ }^{5}$ Infectious Diseases Division, Department of Medicine, University of Pennsylvania Perelman School of Medicine

\section{Keywords}

Telehealth, hospital readmission, hospitalization, heart failure, home health

\section{Summary}

Background: The reduction of all-cause hospital readmission among heart failure (HF) patients is a national priority. Telehealth is one strategy employed to impact this sought-after patient outcome. Prior research indicates varied results on all-cause hospital readmission highlighting the need to understand telehealth processes and optimal strategies in improving patient outcomes.

Objectives: The purpose of this paper is to describe how one Medicare-certified home health agency launched and maintains a telehealth program intended to reduce all-cause 30-day hospital readmissions among HF patients receiving skilled home health and report its impact on patient outcomes.

Methods: Using the Transitional Care Model as a guide, the telehealth program employs a 4G wireless tablet-based system that collects patient vital signs (weight, heart rate, blood pressure and blood oxygenation) via wireless peripherals, and is preloaded with subjective questions related to $\mathrm{HF}$ and symptoms and instructional videos.

Results: Year one all-cause 30-day readmission rate was 19.3\%. Fiscal year 2015 ended with an all-cause 30 -day readmission rate of $5.2 \%$, a reduction by 14 percentage points (a $73 \%$ relative reduction) in three years. Telehealth is now an integral part of the University of Pennsylvania Health System's readmission reduction program.

Conclusions: Telehealth was associated with a reduction in all-cause 30-day readmission for one mid-sized Medicare-certified home health agency. A description of the program is presented as well as lessons learned that have significantly contributed to this program's success. Future expansion of the program is planned. Telehealth is a promising approach to caring for a chronically ill population while improving a patient's ability for self-care.

\section{Correspondence to:}

Usavadee Asdornwised, PhD

Mahidol University,

Bangkok

Thailand;

Email: usavadee.asd@mahidol.ac.th
Appl Clin Inform 2016; 7: 238-247

received: November 20, 2015

accepted: February 2, 2016

published: April 20, 2016

Citation: O'Connor M, Asdornwised U, Dempsey ML, Huffenberger A, Jost S, Flynn D Norris A. Using telehealth to reduce all-cause 30-day hospital readmissions among heart failure patients receiving skilled home health services. Appl Clin Inform 2016; 7: 238-247

http://dx.doi.org/10.4338/ACl-2015-11-SOA-0157 


\section{Background}

Over 5.7 million Americans aged 20 years or older suffer from heart failure (HF) with an expected increase of $46 \%$ by 2030 . Hospital discharges with a primary diagnosis of HF rose from 877,000 in 1996 to $1,023,000$ in 2010. The estimated total cost of HF in the United States exceeded $\$ 30$ billion in 2012 and is projected to be $\$ 70$ billion by 2030 [1]. Heart failure is the primary diagnosis for $4.3 \%$ of home health episodes [2] and is among the top ten most common diagnoses related groups for Medicare beneficiaries discharged from an acute care setting to home health [3]. The Center for the Medicare and Medicaid spends \$17.5 billion per year on 30-day readmissions[4] and has implemented the Hospital Readmissions Reduction Program to reduce payments to hospitals with excess Medicare beneficiary 30-day readmissions for HF [5]. Approximately $25 \%$ of HF patients are readmitted to a hospital within 30 days of discharge [6] which is higher than the estimated 20\% 30-day readmission rate for the general Medicare population [7] and could be the result of insufficient care and/or transition process failure of $\operatorname{HF}$ patients $[8,9,10]$. Similarly, Madigan and colleagues found $26 \%$ of HF patients receiving home health are readmitted within 30 days of hospital discharge [11]. Furthermore, HF represents the highest proportion of all 30-day readmissions among Medicare beneficiaries7 making the reduction of HF patient readmission rates a national priority. Without effective care transitions from hospital to home, generally considered a vulnerable time for HF patients, poor outcomes following discharge such as increased health care utilization, caregiver burden and increased costs may occur [12].

Prior findings indicate that among home health patients readmitted within 30 days of hospital discharge, $68 \%$ of them were readmitted within the first 14 days of home health services [13] making early and targeted intervention critical. Telehealth is one such targeted intervention. Telehealth is defined by the Department of Health and Human Services as "the use of electronic information and telecommunications technologies to support long-distance clinical health care, patient and professional health-related education, public health and health administration." [14] Telehealth is often employed to "promote early detection of clinical decompensation in patients with HF, allowing for timely intervention to prevent mortality events or further deterioration of the patient's condition necessitating hospitalization and use of more resources." [15]. A growing body of evidence indicates that telehealth often provides timely and efficient health care to older adults reducing the need for health care utilization [16]. A recent meta-analysis of 15 systematic reviews published between 2003 and 2013 indicates TH reduces HF-related hospital admissions compared to usual care [15]. Despite the promising reduction of hospital admissions, Kitsiou and colleagues highlight the need to understand telehealth processes and optimal strategies in improving patient outcomes [15]. This report will begin to address this knowledge gap.

\section{Objectives}

The purpose of this paper is to describe how one Medicare-certified home health agency launched and maintains a telehealth program intended to reduce all-cause 30-day hospital readmission among HF patients. The lessons learned and process improvement strategies that have been implemented to maintain our telehealth program's success are presented as the science of optimal telehealth operations evolves.

\section{Methods}

\subsection{Conceptual framework}

The framework guiding this study is derived from the Transitional Care Model (TCM) [12, 17] which focuses on improving the care and outcomes of high-risk, high-cost, and high volume client groups. Transitional care is designed to support continuity of care across settings among a multidisciplinary health care team among vulnerable populations considered high risk for poor outcomes. The TCM is one approach found to successfully reduce 30-day hospital readmissions [12]. The TCM 
model is being used for this program because it incorporates: ongoing monitoring and management of health; patient education regarding symptoms, diet, medication, and lifestyle; and is dependent upon collaboration and consultation among health care providers.

\subsection{Home Health Agency Description}

Penn Care at Home is a moderate-sized Medicare-certified home health agency affiliated with the University of Pennsylvania Health System in Philadelphia. This large, academic health system includes a medical school, physician practices, four hospitals, and Penn Care at Home, a Medicarecertified skilled home health agency. Penn Care at Home provides skilled nursing services, rehabilitation therapies, home health aide and social work services to a five-county area in Pennsylvania. Additional services provided by the home health agency include palliative care, home hospice, inpatient hospice, and infusion services. In fiscal year 2015, Penn Care at Home made 216,197 home health visits, including 114,048 skilled nursing visits. HF is the agency's second most common diagnosis, preceded only by joint replacement.

\subsection{Telehealth Program Description}

Penn Care at Home's remote monitoring telehealth program was initiated in September of 2010 and is aimed at reducing all-cause 30-day readmission among HF patients. The program is an intrahealth system collaboration between Penn Care at Home and Penn E-Lert, the health system's teleICU. To be considered for the telehealth program a home health patient has to meet the following criteria:

1. speak English;

2. have a New York Health Association functional classification of II-IV or be a high risk for readmission;

3. be able to stand on a scale and safely use the monitoring equipment, either with or without caregiver assistance;

4. willing to participate in home monitoring; and

5. have a home environment that could safely accommodate the monitoring equipment.

Patients receive telehealth monitoring while still receiving skilled home health services as long as they continue to meet inclusion criteria.

The telehealth program is intended to reduce all-cause 30 -day readmission rates among HF patients. Initial equipment employed was a moderate sized monitoring unit reliant upon a landline telephone, broad-band cable internet or $3 \mathrm{G}$ wireless card. Wired peripheral devices included a weight scale, blood pressure device and pulse oximeter. In 2014 all telehealth equipment was converted to a $4 \mathrm{G}$ wireless tablet-based system that collects patient vital signs (weight, heart rate, blood pressure and blood oxygenation) via wireless peripherals, and is preloaded with subjective questions related to HF and symptoms. The tablet software includes instructional videos related to the diagnosis of HF, medication compliance and the avoidance of sodium. These videos are identical to the videos shown via the health system's closed circuit television to provide continuity in patient education while patients are hospitalized. The monitoring device promotes early detection of clinical decompensation in patients with HF, allowing for timely intervention to prevent further deterioration of the patient's condition necessitating hospitalization and use of more resources. The program began in 2010 with the purchase of 25 monitors. Today, Penn Care at Home has 105 monitors available for use.

The recorded data is transmitted daily in real-time to the telehealth team via a central secure web portal, located within the health system's teleICU. The telehealth team members collaborate with patients, the home health case manager and providers to identify goals and strategies to avoid a hospital readmission if possible. The telehealth nurses provide patients with coaching cues via the telephone when additional teaching needs are identified. The biometric and subjective question data is reviewed daily, including weekends. Data related to hospital admissions is captured via the health system's electronic health record. Hospital admissions outside of the health system are reported to telehealth personnel by patients, caregivers and/or the home health case manager. 
Telehealth personnel include two registered nurses and two telehealth liaisons. The telehealth monitoring process includes:

1. daily review of all patient data;

2. telehealth nurse contacts the patient daily if biometric trends or subjective questions are outside the patient's normal parameters;

3. elicits additional information regarding their 24 hour diet recall, salt intake, symptoms and medication compliance;

4. changes in condition are communicated to the home health case manager and the physician or nurse practitioner;

5. medication and diet changes are made to the plan of care and physician or nurse practitioner office visits are scheduled as needed;

6. home care case manager schedules follow up visit in the home as needed ( $\triangleright$ Figure 1 ).

HF patients receive usual care (skilled home health only) if the above criteria is not met. Finally, Penn Care at Home prioritizes telehealth for patients within 30 days of hospital discharge as the equipment is a limited resource.

The telehealth program actively engages HF patients intending to teach self-care so that when the equipment is removed, they are able to self-manage their chronic illness. The teaching specifically focuses on four components including personal goal setting, self-monitoring, management of symptoms, and reporting changes to their physician or care team.

\section{Results}

\subsection{Hospitalization and Telehealth Length of Stay}

Since the program's implementation, $818 \mathrm{HF}$ patients have received remote telehealth monitoring ( Table 1). Collection of readmission data began in 2011. The year one all-cause 30-day readmission rate was 19.3\% (fiscal year 2011-2012) among HF patients. The all-cause 30-day readmission rate for fiscal year ending 2015 for HF patients receiving telehealth is $5.2 \%$, a reduction by 14 percentage points (a 73\% relative reduction) in three years ( Figure 2). We began collecting telehealth length of stay in March 2012. The telehealth mean length of stay at that time was 94.3 days. The telehealth mean length of stay ending fiscal year 2015 was 62.9 days. During this same time period, the all-cause 30-day readmission rate for HF patients across the health system stayed relatively unchanged from fiscal years 2011 to 2015 , averaging $17.7 \%$ (range $16.9 \%$ to $18.1 \%$ ).

\subsection{Telehealth Program Process Improvement}

Since the program's inception, the telehealth team has routinely and consistently looked to improve processes and improve patient outcomes. The major components of our telehealth process improvement include individual patient 30-day readmission review and efficient processes evaluation. On a monthly basis readmission data is reviewed collaboratively by clinical and administrative personnel. Each 30-day readmission is evaluated for what telehealth could have done differently to prevent the readmission. The team looks for trends and takes action when an amenable trend is identified. If the amenable trend lies with the skilled home health clinician, administrative personnel contact the clinician and or their supervisor to make them aware of the trend.

The second process improvement activity consistently performed is the evaluation of processes. The telehealth team routinely evaluates each process such as patient data review, patient contacts, coaching and hospitalization reporting for efficiency and accuracy. For example, in 2015 the duties related to patient enrollment and data entry were reassigned from the registered nurses to the telehealth liaison role. Process evaluation also includes examining the effectiveness of the telehealth equipment which is described below. 


\subsection{Contributions to the Telehealth Program's Success}

There are several factors believed to have contributed to telehealth's association with reduced 30-day readmission. The primary factor is our excellent telehealth clinicians who are vigilant in their daily review of each individual's data and evaluation of the parameters considered normal for that person. It is not unusual for our clinicians to 'go the extra mile' to be certain the best plan is in place for each HF patient on service. Our monthly evaluation of the all-cause 30-day readmission rate also contributes greatly to our success as does our frequent evaluation of the program overall. The administrative and clinical team routinely seeks efficiencies and innovation in our processes. One such innovation was the purchase of a $4 \mathrm{G}$ wireless tablet-based system with wireless peripherals that has eliminated data transmission failures and improved patient adherence to the daily monitoring activities.

The all-cause 30-day readmission rate dropped gradually between fiscal years 2011 and 2013 by $3.8 \%$ ( Figure 2). The reduction was more dramatic after fiscal year 2013 (7.6\% reduction) which is when we implemented the wireless $4 \mathrm{G}$ tablet. This tablet is not reliant upon internet access and is therefore, less likely to result in transmission failures. The $4 \mathrm{G}$ tablet is also very easy for patients to use. Finally, having the health system's commitment and dedication of resources to purchase the updated equipment and to employ telehealth personnel is critical to the continuation of the program and crucial to its ongoing success.

\subsection{Lessons Learned}

The initial telehealth program was not an instant success but rather a journey of interprofessional collaboration toward what was believed possible. Among the most important lesson learned was the significance of physician, nurse practitioner and home health case manager trust and support of the program. This critical factor was not initially present but gained over time via reliable and consistent communication among the interprofessional team members. Over time, the clinical team learned to trust and the relay on telehealth monitoring in managing these chronically ill HF patients. In addition, case conferences with home health case managers are conducted when warranted and feasible, especially for telehealth patients who have been on-service for an extended period of time. Monthly evaluation of patient outcomes and trends was another process learned in order to continuously improve our outcomes. Finally, patient engagement with the telehealth staff and their responsiveness to coaching cues was an important lesson to learn as it contributes greatly to their ability to achieve self-care. Having "user-friendly" telehealth equipment is key to the patient's ability to be engaged with the telehealth program.

\section{Discussion}

Telehealth conceptualized by the transitional care model is a useful intervention for patients with chronic illness such as HF. Despite the reduction in HF-related readmissions reported by this team and Kitsiou and colleagues [15] conflicting published evidence indicates some telehealth endeavors to be ineffective in reducing hospital admissions. This controversy is believed to be the reason why telehealth is not yet a standard of care in managing HF patients. 18 It is possible telehealth processes can contribute greatly to a programs' success in patient outcomes; this article attempts to address this gap in knowledge.

However, at Penn Care at Home, telehealth is associated with reducing all-cause 30-day readmission among HF patients receiving skilled home health services. Our findings are consistent with those of a recent study that reduced all-cause readmission from $21 \%$ for non-telehealth patients to $10 \%$ for telehealth patients [19]. Vigilant clinicians, efficient processes, including collaboration with the health system's existing teleICU program, and interprofessional communication have contributed significantly to the programs' success. These findings are supported by those of Burke and Coleman [20] that report creating an effective team is one best practice contributing to the success of interventions designed to reduce hospital readmission. Several factors have contributed to this programs' success including employment of a user friendly $4 \mathrm{G}$ tablet-based system, frequent and 
consistent evaluation of program processes and outcomes and a committed health system to support the program's efforts.

Finally, several studies have shown reductions in HF-related readmissions only [15]. We attribute our success with all-cause readmission to the moderate size of our program, but mostly to the vigilance of the telehealth clinical staff and the collaboration that exists among them and the patient care team including the home health case managers and physicians.

\subsection{Limitations}

Despite this programs success, there are limitations that must be acknowledged. Only data from one Medicare-certified skilled home health agency within a larger northeastern health system was considered. We did not adjust for any potential confounding factors such as patient age, level of education, or length of time with HF. Also, some hospitalizations occurring outside of the University of Pennsylvania Health System could have been missed. Finally, it is possible that the Affordable Care Act and accountable care concepts resulted in changes on non-telehealth related issues which, in turn, contributed to the reductions in 30-day readmissions. Despite the limitations, this project furthers our understanding of a successful telehealth program in reducing hospitalization among heart failure patients.

\subsection{Future Directions}

The University of Pennsylvania Health System has recently expanded the telehealth program to include other chronically ill patients including cirrhosis, cardio-thoracic surgery and oncology patients. Additional patient populations in consideration are those with chronic obstructive pulmonary disease, hypertension, and diabetes. Future research should include further analysis of 30-day readmission and the impact time to install of telehealth equipment has on patient outcomes. It would also be beneficial to expand the process improvement efforts to include the home health case managers in the 30-day readmission review.

\section{Conclusions}

Penn Care at Home's all-cause 30-day readmission rate has steadily declined since the program's inception and has become an integral part of the University of Pennsylvania Health Systems' 30-day readmission reduction efforts. Several contributing factors and key lessons learned attributed to this programs continued success. This telehealth program is expected to continue to expand its efforts to include additional chronically ill patient populations at risk for 30-day readmission. Overall, Penn Care at Home has found telehealth to be a promising approach to caring for a chronically ill population while improving the patient's ability for self-care.

\section{Conflicts of Interest}

All authors declare that they have no conflicts of interest in this project.

\section{Human Subjects Protections}

This project was reviewed and determined to qualify as quality improvement by the University of Pennsylvania's Institutional Review Board.

\section{Acknowledgements}

The authors would like to acknowledge and thank the University of Pennsylvania Health System for their support of this program. 


\section{Telehealth Program Criteria}

1) Speak English

2) NYHA functional class II - IV or be at high risk for readmission

3) Be able to stand on a scale and safely use the equipment, either with our without caregiver assistance

4) Willing to participate in home monitoring

5) Have a home environment that can safely accommodate the monitoring equipment

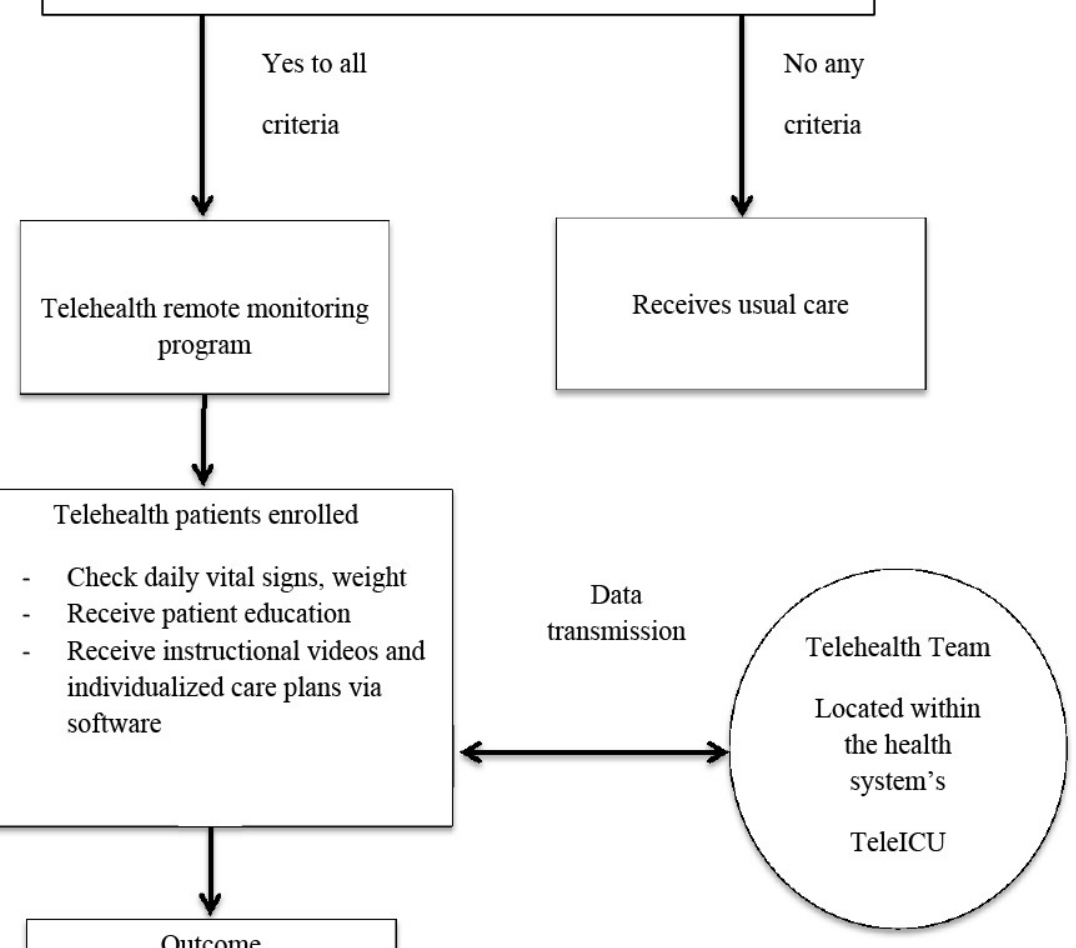

All-cause 30-day readmission rate reduction

Fig. 1 Flow Chart of Telehealth Program 
State of the Art / Best Practice Paper - H3IT

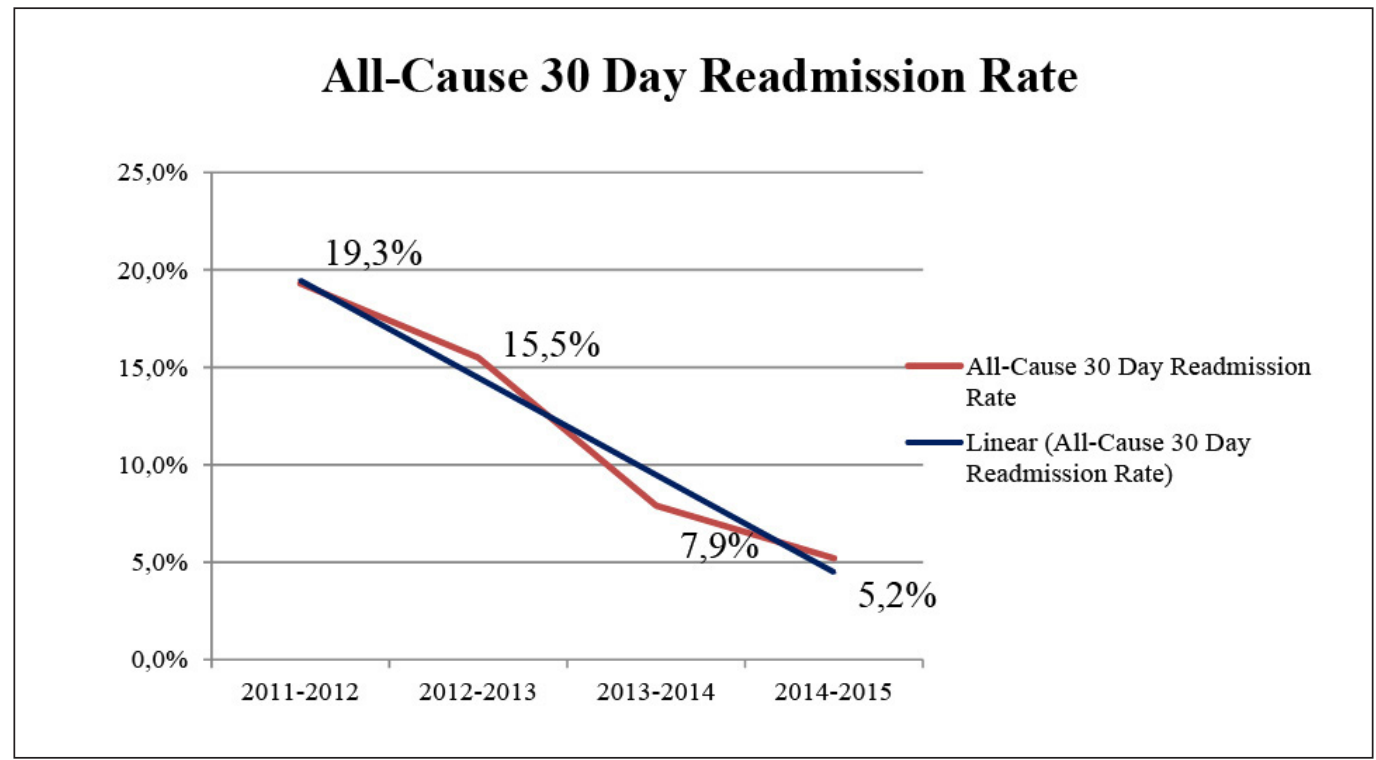

Fig. 2 All-Cause 30 Day Readmission Rate from Fiscal year 2011 - 2015 
State of the Art/ Best Practice Paper - H3IT Special Topic

Table 1 Number of HF Patients Monitored

\begin{tabular}{|l|r|}
\hline Year & $\begin{array}{l}\text { Number of HF Patients } \\
\text { Monitored }\end{array}$ \\
\hline 2011 & 84 \\
\hline 2012 & 151 \\
\hline 2013 & 167 \\
\hline 2014 & 187 \\
\hline $2015^{*}$ & 229 \\
\hline
\end{tabular}

*Ending 10/31/2015 


\section{References}

1. Mozaffarian D, Benjamin EJ, Go AS, Arnett DK, Blaha MJ, Cushman M, Ferranti S, Després JP, Fullerton HJ, Howard VJ, Huffman MD, Judd SE, Kissela BM, Lackland DT, Lichtman JH, Lisabeth LD, Lui S, Mackey RH, Matchar DB, McGuire DK, Mohler ER, Moy CS, Munter P, Mussolino ME, Nasir K, Nichol G, Neumar RW, Palaniappan L, Pandey DK, Reeves MJ, Rodriguez CJ, Sorlie S, Stein J, Towfighi A, Turan TN, Virani SS, Willey JZ, Woo D, Yeh, RW, Turner M. Heart disease and stroke statistics - 2015 update: A report from the American Heart Association, 2015. Retrieved from http://circ.ahajournals.org/content/ early/2014/12/18/CIR.0000000000000152.full.pdf+html

2. Caffrey C, Sengupta M, Moss A, Harris-Kojetin L, Valverde R. Home health care and discharge hospice care patients: United States, 2000 and 2007. National Health Statics Report, 2011; 38: 1-27.

3. Centers for Medicare and Medicaid Services. Chronic conditions among Medicare beneficiaries: Chartbook 2012. Retrieved from https://www.cms.gov/research-statistics-data-and-systems/statistics-trendsand-reports/chronic-conditions/downloads/2012chartbook.pdf

4. Centers for Medicare \& Medicaid Services, Office of Information Products and Data Analytics. National Medicare readmission findings: Recent data and trends, 2012. Retrieved from http://www.academyhealth. org/files/2012/sunday/brennan.pdf

5. Medicare Payment and Advisory Commission. Report to the congress: Medicare payment policy, 2013 Retrieved from http://www.medpac.gov/documents/reports/mar13_entirereport.pdf?sfvrsn=0

6. Krumholz HM, Merrill AR, Schone EM, Schreiner GM, Chen J, Bradley EH, Wang Y, Wang YF, Lin Z, Straube BM, Rapp MT, Norman ST, Drye EE. Patterns of hospital performance in acute myocardial infarction and heart failure 30-day mortality and readmission. Circ Cardiovasc Qual Outcomes 2009; 2: 407-413.

7. Jencks SF, Williams, MV, Coleman EA. Rehospitalizations among patients in the Medicare fee-for-service program. N Engl J Med 2009; 360: 1418-1428.

8. Moore C, McGinn T, Halm E. Tying up loose ends discharging patients with unresolved medical issues. Arch Intern Med 2007; 167: 1305-1311.

9. Coleman EA, Parry C, Chalmers S, Min SJ. The care transitions intervention: Results of a randomized controlled trail. Arch Intern Med 2006; 166(17): 1822-1828.

10. Davidson PM, Cockburn, J, Newton PJ. Unmet needs following hospitalization with heart failure: Implications for clinical assessment and program planning. J Cardiovasc Nurs 2008; 23(6): 541-546.

11. Madigan EA, Gordon NH, Fortinsky RH, Koroukian SM, Pina I, Riggs JS. Rehospitalization in a national population of home health care patients with heart failure. Health Serv Res 2012; 47(6): 2316-2338.

12.Naylor MD, Aiken LH, Kurtzman ET, Olds DM, Hirschman KB. The care span: The importance of transitional care in achieving health reform. Health Aff (Millwood) 2011; 30(4): 746-754.

13. O'Connor M, Hanon AL, Bowles KB. Impact of frontloading of skilled nursing visits on the incidence of 30-day hospital readmission. Geriatr Nurs 2014; 35; S37-S44.

14. Health Resources and Service Administration (HRSA) rural health. Retrieved from www.hrsa.gov/rural health/about/telehealth.

15. Kitsiou S, Pare, Jaana, M. Effects of home telemonitoring interventions on patients with chronic heart failure: An overview of systematic reviews. J Med Internet Res 2015; 17(3): e63.

16. Bowles, KB, Dykes, P, Demiris, G. The use of health information technology to improve care and outcomes for older adults. Res in Gerontol Nurs 2015; 8(1): 5-10. doi: 10.3928/19404921-20121222-01

17. Naylor MD, Brooten DA, Campbell RL, Maislin G, McCauley KM, Schwartz JS. Transitional care of older adults hospitalized with heart failure: a randomized controlled trail. J Am Geriatr Soc 2004; 52(5): 675-684.

18.O'Connor M. Hospitalization among Medicare-reimbursed skilled home health recipients. Home Health Care Manag Prac 2012; 24(1); 25-35. doi:10.1177/1084822311419498

19.Thomason TR, Hawkins SY, Perkins KE, Hamilton K, Nelson, B. Home telehealth and hospital readmissions. Home Healthc Now 2015; 33(1): 20-26.

20. Burke RE, Coleman EA. Interventions to decrease hospital readmissions: keys for cost-effectiveness. JAMA Intern Med 2013; (8): 695-698. 